\title{
The expandable metal stent for tracheal obstruction
}

\author{
A E Boothroyd, R Edwards, A J Petros, R Franks
}

\begin{abstract}
A 10 month old boy with stridor persisting from birth was found to have tracheal narrowing secondary to myofibromatosis of the tracheal wall. An expandable metal stent was positioned across the tracheal stenosis with immediate clinical improvement. There were no complications relating to stent insertion. The child remained clinically asymptomatic and repeat bronchoscopy at nine months' follow up showed that the stent had become completely endothelialised with no evidence of granuloma formation.

(Arch Dis Child 1995; 72: 435-436)
\end{abstract}

Keywords: trachea, stent, myofibromatosis.

The use of endoscopically inserted expandable metal stents for tracheobronchial strictures has been reported in adults with good relief of clinical symptoms and few complications. The adult cases described have been mainly for patients with malignant disease but there are also reports of successful stenting of benign lesions such as post-transplantation anastomotic strictures and fibroinflammatory stenosis. There are very few published reports of endoscopic placement of expandable stents in the malacic segment of infants and neonates. ${ }^{1}$ However, with the developments in the management of the neonatal airway more infants with airway collapse are surviving. ${ }^{2}$ This report describes an infant with isolated myofibromatosis of the distal trachea which was successfully treated with a Gianturco stent.

Royal Liverpool

Children's NHS Trust

Eaton Road, Liverpool L12 2AP, Department of Radiology

A E Boothroyd

Cardiac Intensive Care Unit

A J Petros

Department of Cardiac Surgery R Franks

Department of Radiology, Royal Liverpool University

Hospital

R Edwards

Correspondence to: Dr Boothroyd.

Accepted 8 December 1994

\section{Case report}

A 10 month old infant presented with inspiratory stridor since birth. $\mathrm{He}$ had been thoroughly investigated for failure to thrive at the referring hospital with no conclusion. During feeding and sleeping, peripheral saturations fell to $88 \%$. Rigid bronchoscopy revealed a severe anteroposterior narrowing of the trachea from about 3 to $1 \mathrm{~cm}$ above the carina. Echocardiography and computed tomography failed to reveal a cause for the tracheal stenosis. Magnetic resonance demonstrated increased signal within a thickened area. The anteroposterior diameter of the trachea at this level was 1-2 mm (fig 1). No anomalous vessels were seen. The mass was noted to be contiguous with the ascending aorta and transverse arch. Bronchoscopic biopsy was therefore considered unsafe.
Via a median sternotomy the upper trachea appeared normal. The lower third was thickened and biopsy specimens were taken from the thickened tracheal wall. Histology revealed dense hyalinised fibrocollagenous tissue indicative of myofibromatosis. Resection of the involved tracheal segment was considered but not felt to be a practical option. A modified Gianturco-Rosch Z-stent (Wm Cook Ltd), was introduced bronchoscopically, and under fluoroscopic control deployed across the stenosis. The unconstrained stent diameter was $14 \mathrm{~mm}$. There was an immediate improvement in ventilatory function with a fall in the arterial carbon dioxide tension from 9.33 to $5.33 \mathrm{kPa}$, the patient was extubated without difficulty and his stridor resolved. Frontal and lateral chest radiography (figs $2 \mathrm{~A}$ and $2 \mathrm{~B}$ ) showed the stent well expanded and to lie within the distal trachea across the stenosis. At nine months of follow up the child's respiratory status remains stable and significant improvement in weight and developmental assessment has occurred. A repeat bronchoscopy was performed and showed that the stent had become completely endothelialised with no evidence of granuloma formation.

\section{Discussion}

Infantile fibromatosis is an unusual condition generally presenting in the newborn period. Approximately half of the affected infants have solitary lesions and the remainder have more widespread visceral involvement. ${ }^{3}$ However, unless the nodules obstruct bronchi or bowel or involve a vital organ such as the heart they do not pose a threat to life.

Although spontaneous regression of lesions is normal, the clinical features of extreme tracheal narrowing in this patient required intervention. Resection of the long involved segment was considered inappropriate. It was felt that in such

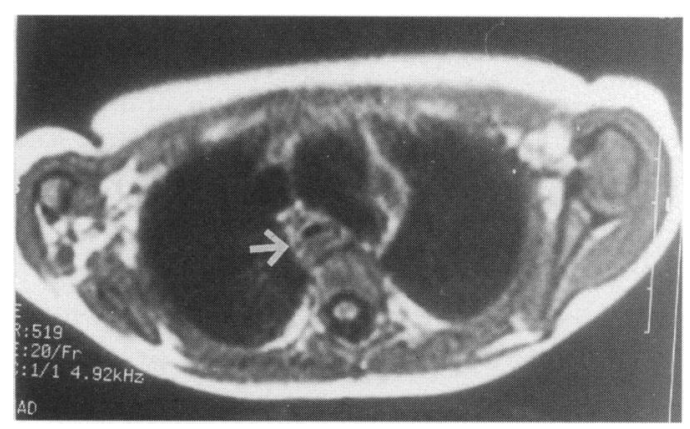

Figure $1 \quad T 1$ weighted magnetic resonance image showing thickening of the distal tracheal wall (arrow). The area of abnormal signal is contiguous with the ascending aorta and transverse arch. 


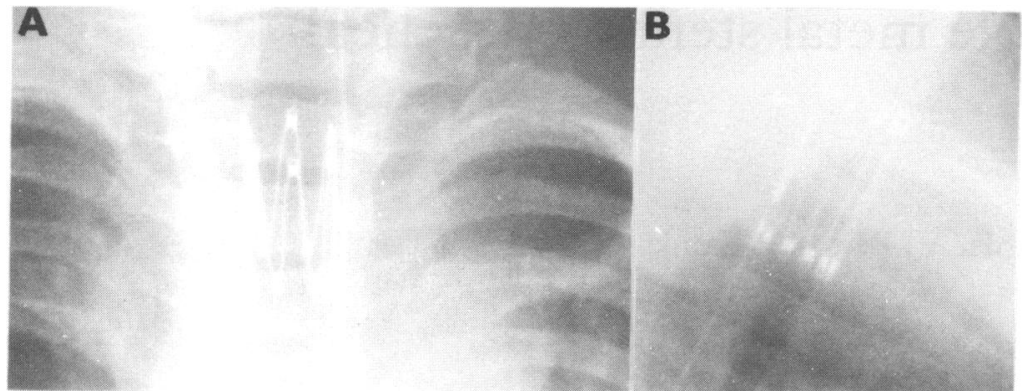

Figure 2 (A) Frontal and (B) lateral chest radiographs demonstrating the stent expanded within the tracheal lumen. proliferation has necessitated stent removal. ${ }^{11}$ One of the two neonates described by Mair et al died. ${ }^{1}$ Emergency bedside bronchoscopy confirmed a patent stent and no airway collapse or obstruction. Postmortem histological examination revealed a foreign body inflammatory response and microscopic examination revealed sloughing of adjacent respiratory cilia and squamous metaplasia. ${ }^{1}$ These authors have subsequently indicated that significant granulation formation after stent insertion may necessitate subsequent surgery and led them to explore other options including homograft tracheal transplantation. Others also report that granulomata formation and migration can cause long term problems. The potential difficulties of a child outgrowing a stent also have to be addressed in the future (Dr Ethan Phelan, Deputy Director, Department of Radiology, Royal Children's Hospital, Melbourne, personal communication to RE).

The combination of these histological features plus the low surface area of the stent suggests that mucociliary clearance is unlikely to be impaired, thus reducing the risk of stent blockage. For the same reason stent removal is probably impractical after 4-6 weeks, and in this case a larger stent diameter was chosen to accommodate growth. There is no specific paediatric tracheobronchial stent currently available and further improvements in stent design are likely to be necessary.

Tracheobronchial stenting provides another therapeutic option in a difficult clinical situation but requires careful consideration as the long term effects are not known.

1 Mair EA, Parsons DS, Lally KP. Treatment of severe bronchomalacia with expanding endobronchial stents. Aronchomalacia with expanding endobronchial sten

2 Mair EA, Parsons DS. Pediatric tracheobronchomalacia and major airway collapse. Ann Otol Rhinol Laryngol 1992; 101: 300-9.

3 Soper JR, De Silva M. Infantile myofibromatosis: a radiological review. Pediatr Radiol 1993; 23: 189-94.

4 Hudson TM, Vandengriend RA, Springfield DS, et al. Aggressive fibromatosis: evaluation by computed tomography and angiography. Radiology 1984; 150: 495-501.

5 Quinn SF, Erikson SJ, Dee PM, et al. MR imaging in fibromatosis. AfR 1991; 156: 539-42.

6 Wallace MJ, Charnsangavej C, Ogawa $\mathrm{K}$, et al. Tracheobronchial tree: expandable metal stents used in experimental and clinical applications. Radiology 1986; 158: $309-12$.

7 Simonds AK, Irving JD, Clarke SW, et al. Use of expandable metal stents in the treatment of bronchial obstrucable metal stents in the treat

8 Varela A, Maynar M, Irving D, et al. Use of Gianturco selfexpandable stent in the tracheobronchial tree. Ann Thorac expandable stent in the
Surg 1990; 49: 806-9.

9 Mair EA, Parsons DS, Lally KP. Treatment of severe bronchomalacia with expanding stents. Arch Otolaryngol Head Neck Surg 1990; 160: 1087-90.

10 Rauber K, Franke C, Ran WS. Self expanding stainless steel endotracheal stents: an animal study. Cardiovasc Interven Radiol 1989; 12: 274-6.

11 Nashef SAM, Dromer C, Velly J-F, et al. Expanding wire stents in benign tracheobronchial disease: indications and complications. Ann Thorac Surg 1992; 52: 937-40. 